\title{
Análise das características morfométricas da bacia hidrográfica do rio Ipojuca - PE
}

\author{
Analysis of morphometric characteristics of the river basin Ipojuca - PE
}

\author{
DEUS $^{1}$, R. A. S. G.; $\operatorname{COSTA}^{2}$, S. O. S; LOURENÇO ${ }^{3}$, E. R. C.; GOLDFARB ${ }^{4}$, \\ M. C.; DUARTE ${ }^{5}$, C. C.; GOMES ${ }^{6}$, D. D. M.
}

rdolfodeus@gmail.com;

\begin{abstract}
Resumo
Este Trabalho tem como objetivo analisar as características morfométricas da bacia hidrográfica do Rio Ipojuca, localizada no estado de Pernambuco. Foram utilizadas imagens do radar SRTM (Shuttle Radar Topographic Mission) para extração de dados altimétricos. A pesquisa foi desenvolvida A partir de levantamento bibliográfico e processo de aquisição das cenas referentes à área de estudo utilizando o Software ArcGis 10.2.2 para manipulação dos dados morfométricos. A bacia hidrográfica do referido rio possui área total aproximada de $3.433,58 \mathrm{~km}^{2}$ com perímetro $749,6 \mathrm{~km}$, ocupa $3,49 \%$ da área do estado de Pernambuco e perpassa 24 municípios dos quais 12 estão com suas sedes dentro dos limites da bacia. A análise morfométrica aqui desenvolvida permitiu compreender as características físico-naturais e geomorfológicas da bacia do rio Ipojuca, além de oferecer compreensão de sua dinâmica hidrológica, que por sua vez oferece conhecimento do comportamento erosivo existente em toda bacia.
\end{abstract}

Palavras-chave: Análise Morfométrica, Bacia Hidrográfica, Dinâmica Hidrológica.

\begin{abstract}
This work has been to assess the morphometric of the watershed river Ipojuca, in the state of Pernambuco. Radar scenes were used SRTM (Shuttle Radar Topographic Mission) with altimetry data for performing and fostering of the results of the work. From a literature review and purchase the scenes process was used GIS ArcGIS 10.2.2 for handling the data. The watershed in question has an area of 3.433,58 $\mathrm{km}^{2}$ with a perimeter $749,6 \mathrm{~km}$, the watershed occupies $3.49 \%$ of the area of the state of Pernambuco and runs through 24 municipalities of which 12 are with their headquarters within the watershed area. The morphometric analysis developed here this watershed is to understand the physical-natural and geomorphological characteristics, and also provide understanding of the hydrological dynamics of it, which in turn provides knowledge of existing erosive behavior throughout the watershed.
\end{abstract}

Keywords: geomorphological characteristics, remote sensing, hydrological dynamics.

\section{INTRODUÇÃO}

Os recursos hídricos são considerados como recursos não renováveis e de extrema importância para todas as vidas do planeta. Garantir que o mesmo seja utilizado de forma sustentável e consciente tornou-se algo vital e essencial em meio à realidade atual. De acordo com Castro et al (2003) é veemente a necessidade de se desenvolver estudos mais aprofundados nessa temática, tendo em vista que a cada dia que se passa esses recursos estão mais ameaçados por conta das ações não planejadas do homem, sem investimento nem infraestrutura, o que causa sérios transtornos à população.

\footnotetext{
${ }^{1}$ Rodolfo Alexandre da Silva Gomes de Deus, Graduando em Geografia, Universidade de Pernambuco, Garanhuns - PE,Brasil.

2 Samuel Othon de Souza Costa, Mestrando em Geografia, Universidade Federal da Paraíba, João Pessoa - PE, Brasil.

3 Elloise Rackel Costa Lourenço, Doutoranda em Geografia, Universidade Federal da Paraíba, João Pessoa - PE, Brasil.

${ }^{4}$ Maurício Costa Goldfarb, Doutor em Engenharia Mecânica, Universidade de Pernambuco, Garanhuns - PE, Brasil.

5 Cristiana Coutinho Duarte, Doutora em Geografia, Universidade de Pernambuco, Garanhuns - PE, Brasil.

${ }^{6}$ Daniel Dantas Moreira Gomes, Doutor em Geografia, Universidade de Pernambuco, Garanhuns - PE, Brasil.
} 
Diante do exposto, a escolha de bacias hidrográficas como unidades de análise quanto aos processos naturais faz-se necessário, pois uma bacia hidrográfica é um sistema complexo no qual o fluxo de água e de sedimento constituem os seus processos fundamentais e interagem com diversos elementos do sistema em geral, sempre objetivando uma configuração otimizada (LIMA, 2005). Além disso, o estudo das características da bacia em termos quantitativos, por meio da análise morfométrica, facilita a compreensão das inter-relações entres os fatores de forma e os processos hidrológicos da bacia hidrográfica (NASCIMENTO et al, 2013).

De acordo com Gomes $(2014 ; 2015)$ a Análise Morfométrica de bacias hidrográficas contribui de forma direta para a compreensão das características físico-naturais e geomorfológicas da bacia, além de influenciar diretamente no conhecimento da dinâmica hidrológica, que por sua vez acaba se tornando algo de fundamental importância para o conhecimento do comportamento erosivo da bacia hidrográfica. Esse mesmo autor destaca ainda a importância da análise da bacia de forma sistêmica e integrada, uma vez que irá refletir inúmeros processos existentes em sua evolução, bem como determinar com maior clareza a capacidade de suporte e ocupação da mesma, possibilitando, portanto, um melhor aproveitamento de todos os recursos naturais oferecidos pela bacia e ainda criar um diagnóstico adequado sobre a situação dos mesmos.

A bacia hidrográfica do rio Ipojuca ocupa cerca de 3,49\% da área territorial do estado de Pernambuco, além de trespassar 24 municípios, 12 desses com suas sedes localizadas dentro da área da bacia. Desta forma a análise Morfométrica oferece compreensão do objeto de estudo, como o comprimento do canal principal, área, perímetro, declividade média, classes de declividade informações estas que permitem compreender as características físico-naturais da bacia, por se tratar de uma bacia que ocupa uma área bastante significativa do estado, ela acaba por se tornar alvo importante de estudos em Pernambuco. Dentro deste contexto o presente trabalho tem como objeto de estudo a bacia hidrográfica do Rio Ipojuca. Realizando uma análise Morfométrica a partir do estudo da morfologia da bacia e da sua declividade.

De acordo com a Agência Estadual de Planejamento e Pesquisas de Pernambuco CONDEPE/FIDEM (2005), essa bacia está localizada no território do estado de Pernambuco e situa-se entre os paralelos $8^{\circ} 09^{\prime} 50^{\prime \prime}$ e $8^{\circ} 40^{\prime} 20^{\prime \prime}$ de latitude sul, e os meridianos $34^{\circ} 57^{\prime} 52^{\prime}$ ' e $37^{\circ}$ 02' 48" de longitude a oeste de Greenwich (Figura 1). Ocupa uma área de $3.433,58 \mathrm{~km}^{2}$, possui um perímetro de 749,6km, faz divisa ao norte com a bacia hidrográfica do rio Capibaribe, ao sul com as bacias dos rios Una e Sirinhaém, a leste com o segundo e terceiro grupos de bacias hidrográficas de pequenos rios litorâneos e o oceano atlântico e a oeste com as bacias dos rios Ipanema e Moxotó e o Estado da Paraíba. 
Por se tratar de uma bacia hidrográfica de extensão longitudinal bastante expressiva, foi utilizado um mosaico de imagens SRTM (Shuttle Radar Topography Mission). De acordo com Carvalho et al (2004) o uso das imagens de SRTM tem se tornado mais frequente em pesquisas hidrológicos, geomorfológicos, dentre outros, em particular para análises quantitativas e qualitativas do relevo e seus elementos modificadores, em especial na elaboração de mapas hipsométricos, declividades, perfis topográficos, dentre outros produtos relacionados à topografia.

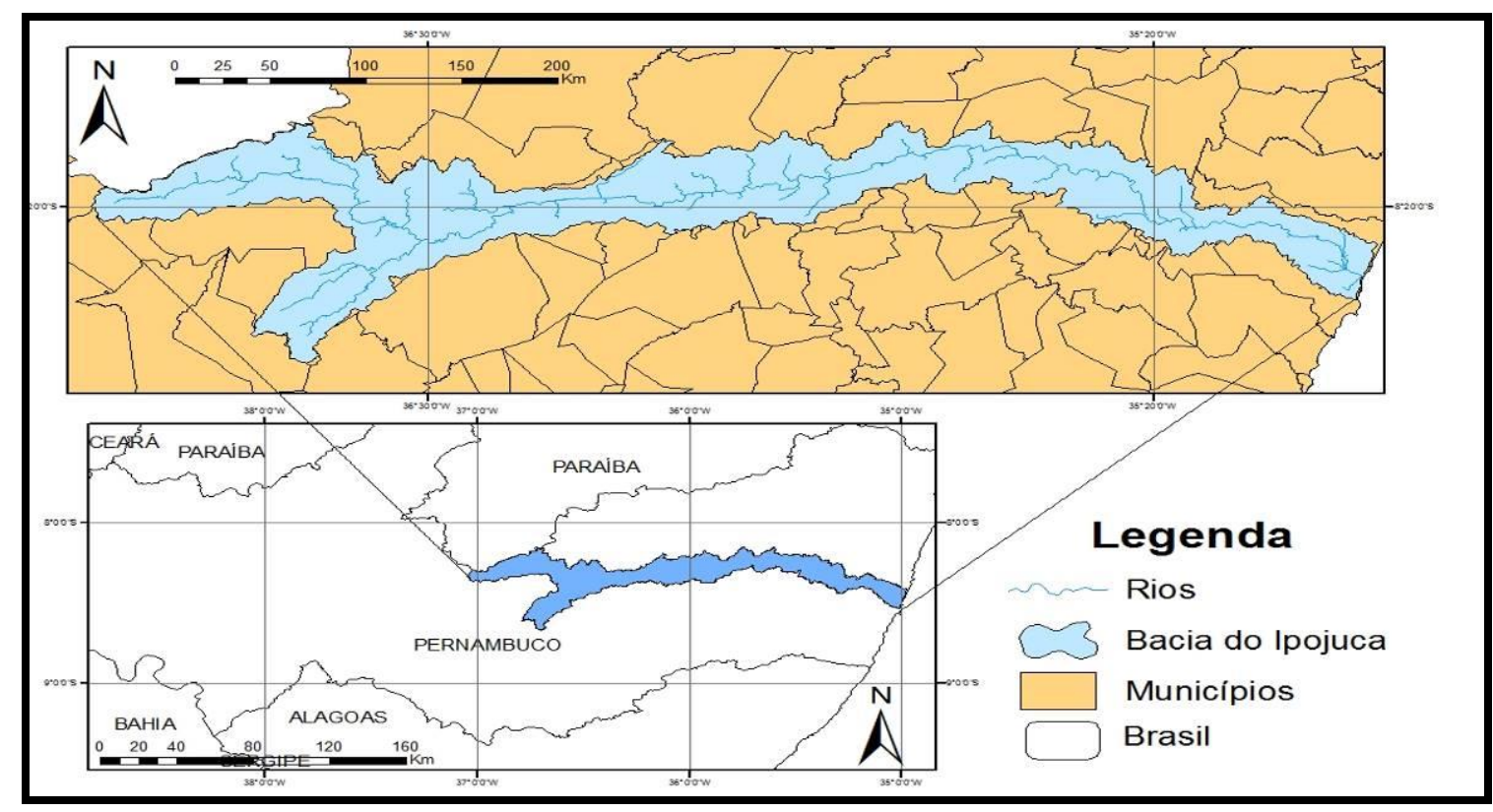

Figura 1 - Mapa de Localização da Bacia Hidrográfica do Rio Ipojuca. Fonte: Autor (2015)

\section{METODOLOGIA}

No processo de desenvolvimento do estudo da bacia do rio Ipojuca o primeiro passo foi o levantamento bibliográfico unido à aquisição de dados cartográficos e de imagens de satélite. Foram consultados artigos científicos, livros dentre outros arquivos que serviram de referencial teórico para a pesquisa.

Para realizar as análises foram utilizadas imagens de SRTM (Shuttle Radar Topographic Mission) que forneceram dados altimétricos de 90 metros, as cenas utilizadas foram: SC-24-X-B e a cena SC-25-V-A. Dentro das análises morfométricas realizadas na bacia hidrográfica do Rio Ipojuca, foi levado em consideração alguns fatores como as características morfológicas do relevo que permitiram avaliar sua área, drenagem, declividade, hierarquia fluvial, altimetria, perímetro e perfil longitudinal. 
Todo o material produzido na pesquisa foi manipulado através do software ArcGis 10.2.2 oferecido pela Environmental Systems Research Institute - ESRI, a partir dele foi possível a criação de mapas de localização, declividade, dentre todos os outros produtos gerados pelo trabalho. Esse SIG (Sistema de Informações Geográficas) permitiu a criação de um banco de dados onde foi possível armazenar todos os dados cartográficos e imagens de satélite que foram levantados nos primeiros passos da pesquisa e permitiu manipulação total deles para criação dos resultados, além de fornecer arcabouço pré-montado para pesquisas posteriores do mesmo objeto.

Todos os dados morfométricos foram obtidos a partir dessa manipulação dos dados colhidos nas fases iniciais em ambiente SIG, proporcionando, portanto, através do banco de dados criado previamente uma extração de informações que acabaram por contribuir diretamente na fomentação de uma análise morfométrica do alvo. Através do software utilizado, foi possível calcular a área da bacia, seu perímetro, criar a hierarquização dos seus canais para se obter outros dados como o comprimento do curso principal, o comprimento total dos canais existentes, para assim fomentar mapas tais como o mapa de classes de declividades que passaram a demonstrar a realidade morfológica existente na bacia do rio Ipojuca.

Por conta da grande extensão longitudinal da bacia, foi necessário utilizar duas cenas do SRTM, que posteriormente à aquisição foram fundidas por processo de criação de mosaico. No contexto da declividade existente na bacia, foi proposto uma classificação para os resultados obtidos, partindo-se do princípio de 6 classes: relevo plano, suave ondulado, ondulado, fortemente ondulado, montanhoso e escarpado. Na tabela 1 é possível observar uma breve descrição de tais classes, relacionadas ao coeficiente em graus que também foi levado em consideração para fomentação do mapa das classes de declividade.

Tabela 1 - Descrição das classes de declividade. Fonte: Gomes et al (2014)

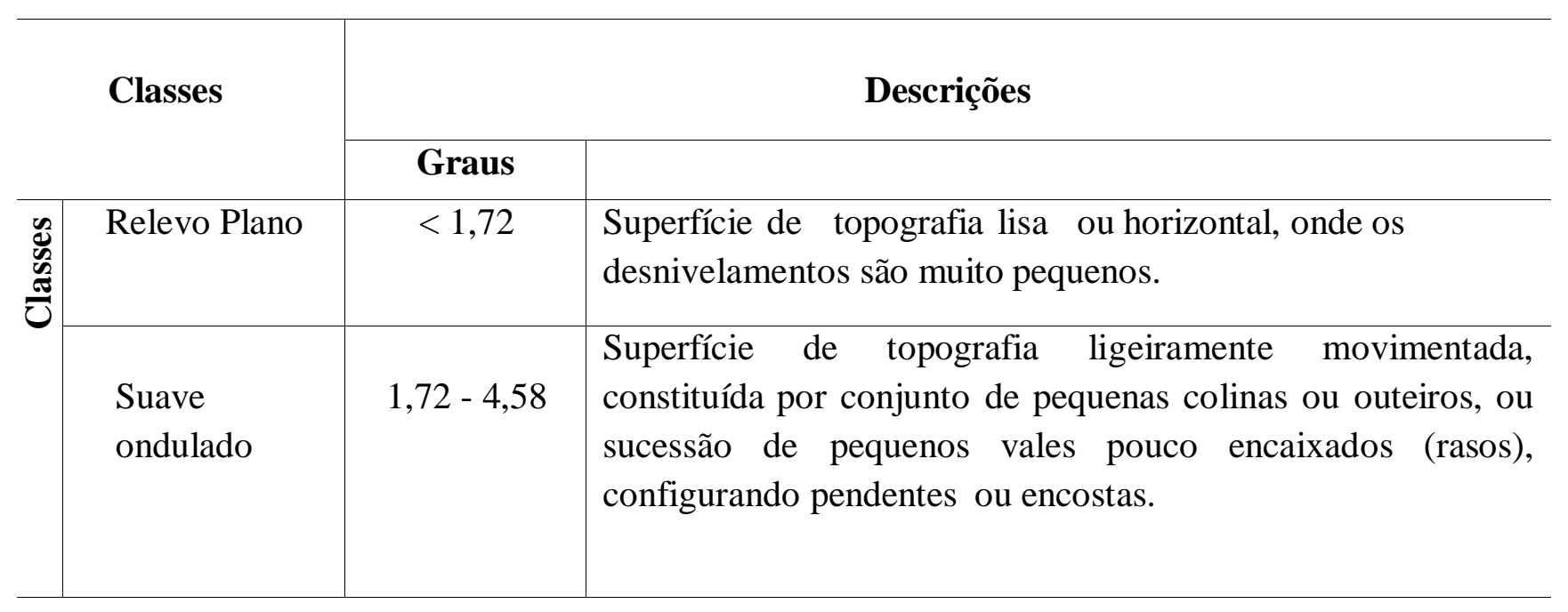




\begin{tabular}{|c|l|l|l}
\hline Ondulado & $4,58-11,31$ & $\begin{array}{l}\text { Superfície de topografia relativamente movimentada, } \\
\text { constituída por conjunto de medianas colinas e outeiros, ou } \\
\text { por interflúvios de pendentes curtas, formadas por vales } \\
\text { encaixados, configurando em todos os casos pendentes ou } \\
\text { encostas. }\end{array}$ \\
\hline $\begin{array}{c}\text { Fortemente } \\
\text { Ondulado }\end{array}$ & $11,31-24,23$ & $\begin{array}{l}\text { Superfície de topografia movimentada, com desníveis fortes, } \\
\text { formadas por conjunto de outeiros ou morros, ou por } \\
\text { superfície entrecortada por vales profundos, configurando } \\
\text { encostas ou pendentes. }\end{array}$ \\
\hline Montanhoso & $24,23-36,87^{\circ}$ & $\begin{array}{l}\text { Superfície de topografia vigorosa, com predomínio de formas } \\
\text { acidentadas, usualmente constituídas por morros, montanhas, } \\
\text { maciços montanhosos e alinhamentos montanhosos, } \\
\text { apresentando desnivelamentos relativamente grandes e } \\
\text { declives fortes ou muito fortes. }\end{array}$ \\
\hline Escarpado & $>36,87^{\circ}$ & $\begin{array}{l}\text { Áreas com predomínio de formas abruptas, compreendendo } \\
\text { superfícies muito íngremes, usualmente ultrapassando 75\%, } \\
\text { tais como: aparados, itaimbés, frentes de cuestas, falésias e } \\
\text { vertentes de declives muito fortes. }\end{array}$ \\
\hline
\end{tabular}

\section{RESULTADOS E DISCUSSÃO}

Nesta pesquisa foram geradas tabelas e mapas visando demonstrar de forma mais clara algumas características da bacia, como hierarquia fluvial, classes de declividade dentre outros fatores que servem de aporte teórico para criação de estudos específicos dentro do contexto da dinâmica hidrológica, e morfogenética da bacia. Na tabela 2 são apresentadas as principais características da bacia.

Tabela 2 - Análise das características morfológicas da bacia. Fonte: Autor (2015)

\begin{tabular}{c|c|c}
\hline Análises & $\begin{array}{c}\text { Unidades de } \\
\text { Medidas }\end{array}$ & $\begin{array}{c}\text { Bacia Hidrográfica do } \\
\text { Ipojuca }\end{array}$ \\
\hline Área & $\mathrm{Km}^{2}$ & $3.433,58$ \\
\hline Perímetro & $\mathrm{Km}$ & 749,6 \\
\hline Comprimento do Canal Principal & $\mathrm{Km}$ & 349 \\
\hline
\end{tabular}


A partir dos resultados obtidos sobre a morfologia da bacia, é possível perceber que o objeto de estudo tem uma área de aproximadamente $3.433 \mathrm{Km}^{2}$. A bacia hidrográfica do rio Ipojuca possui um perímetro de 749,6 Km onde o seu canal principal mede $349 \mathrm{Km}$ de comprimento. Na tabela 3 podemos observar uma análise das características morfométrica da bacia (declividade média, classe de declividade predominante, hierarquia fluvial, perfil longitudinal e o comprimento total de canais).

Tabela 3 - Análise das características morfométricas da bacia. Fonte: Autor (2015)

\begin{tabular}{c|c|c}
\hline Análises & $\begin{array}{c}\text { Unidades de } \\
\text { Medidas }\end{array}$ & $\begin{array}{c}\text { Bacia Hidrográfica do } \\
\text { Ipojuca }\end{array}$ \\
\hline Declividade Média & $\mathrm{m} / \mathrm{Km}$ & 2,51 \\
\hline Classe de Declividade Predominante & Graus & $<1,72^{\circ}-$ Relevo Plano \\
\hline Hierarquia Fluvial & Ordem & 6 \\
\hline Perfil Longitudinal & $\mathrm{Km}$ & 349 \\
\hline Comprimento Total de Canais & $\mathrm{Km}$ & 2721,756 \\
\hline
\end{tabular}

A hierarquia fluvial que tem por base os conceitos de Horton (1945) modificado por Strahler (1952; 1957; 1958), possibilita o ordenamento fluvial, sendo que a ordem da bacia hidrográfica é designada como a ordem do rio que passa pelo exutório, onde na bacia hidrográfica do rio Ipojuca essa representação chega até a $6^{\circ}$ ordem. Esses dados são cruciais para obtenção de outras informações como o comprimento total de canais e o comprimento do canal principal descritos nas tabelas 2 e 3 . A hierarquia fluvial nesse ponto da pesquisa é essencial como processo intermediário para obtenção de dados importantes de uma análise morfométrica, como os citados anteriormente.

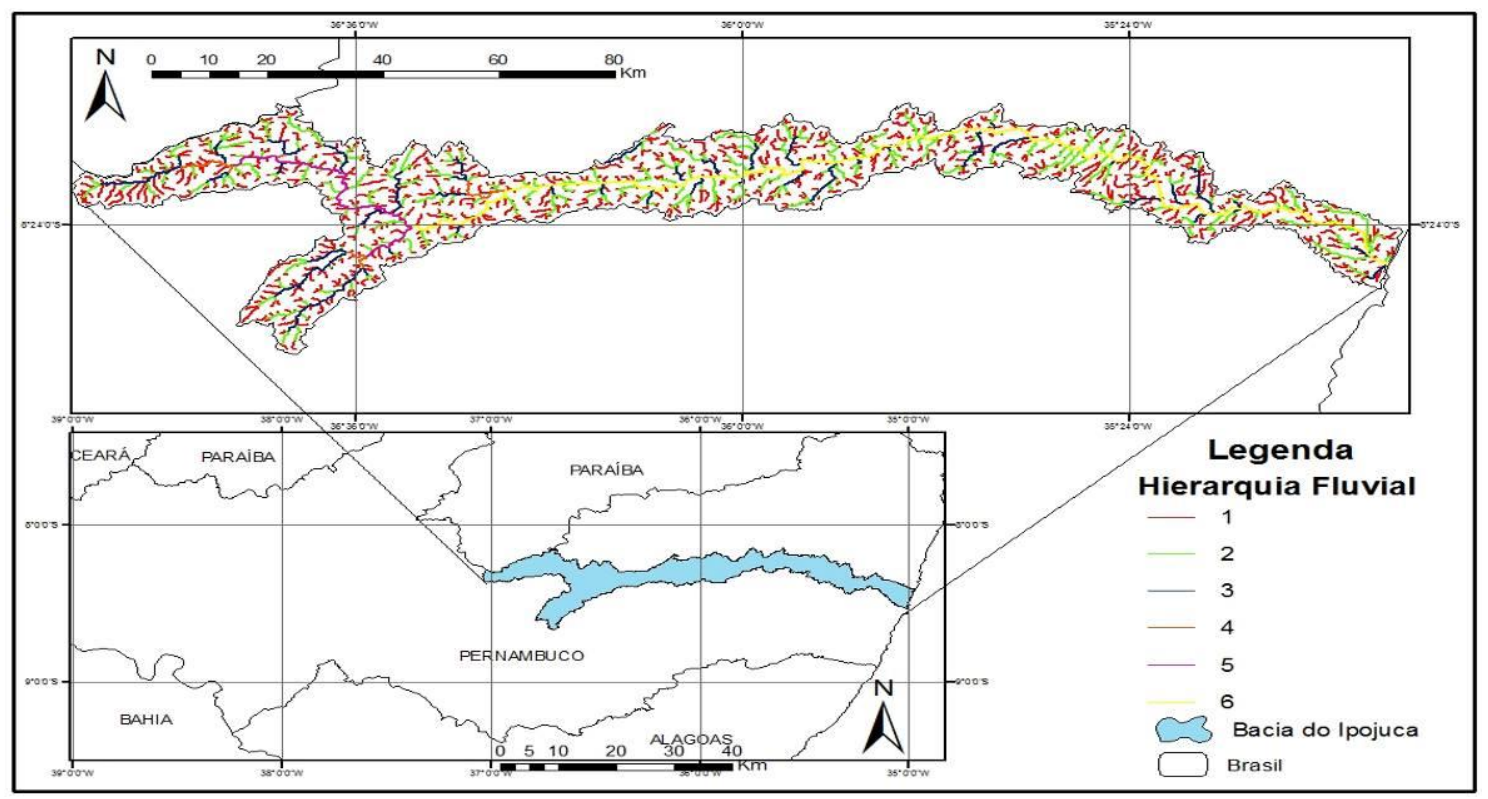


Figura 2 - Mapa da Hierarquia Fluvial da Bacia Hidrográfica do Rio Ipojuca. Fonte: Autor (2015)

A tabela 3 traz os resultados obtidos a partir da manipulação dos dados em ambiente computacional. A bacia do rio Ipojuca apresenta declividade média de $2,51 \mathrm{~m} / \mathrm{Km}$, esse dado é importante, pois o fator declividade influencia na velocidade de fluxo da água. A tabela traz também o valor do perfil longitudinal de $349 \mathrm{Km}$, valor esse que se refere as diferenças altimétricas encontrada ao longo de toda extensão do canal principal, que pode ser observado na figura 4. A partir da hierarquização fluvial foi possível obter os valores dos canais existentes na bacia, e assim calcular o comprimento total dos canais, $2721,756 \mathrm{Km}$. Na fig. 3 é possível observar um mapa de toda a declividade existente na bacia classificada a partir de 6 classes (relevo plano, suave ondulado, ondulado, fortemente ondulado, montanhoso e escarpado).

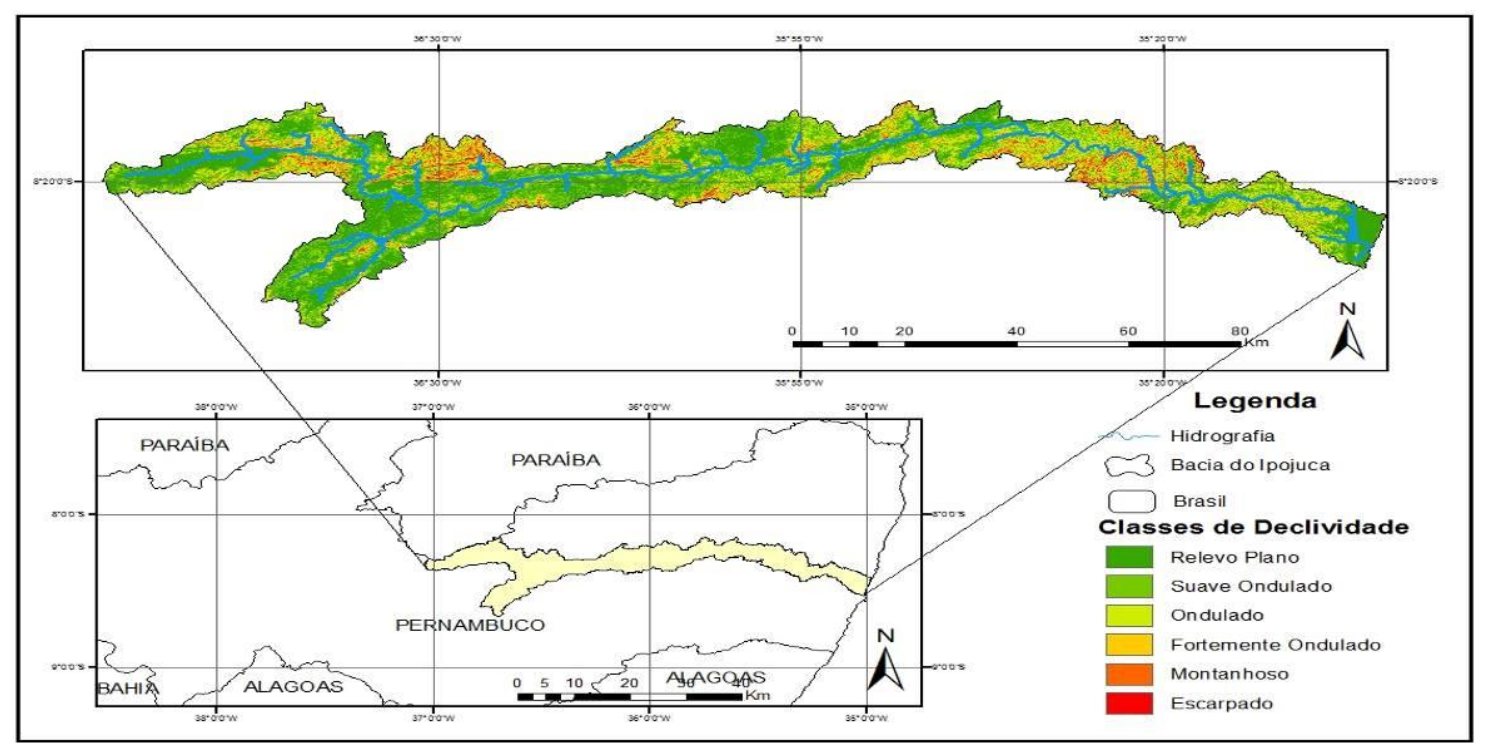

Figura 3 - Classes de Declividade da Bacia Hidrográfica do Ipojuca. Fonte: Autor (2015)

Tais classes foram definidas a partir da relação com o coeficiente em graus, onde se utilizou os valores descritos na tabela 1. Dentro dessas observações foi possível notar que a bacia possui relevo plano, demonstrando assim uma superfície de topografia lisa horizontal, onde os desnivelamentos são ínfimos. Na fig. 4 é possível observar o perfil longitudinal do rio Ipojuca, que de acordo com Silva et al. (2014) possui uma altitude máxima de 877 metros na sua nascente. 


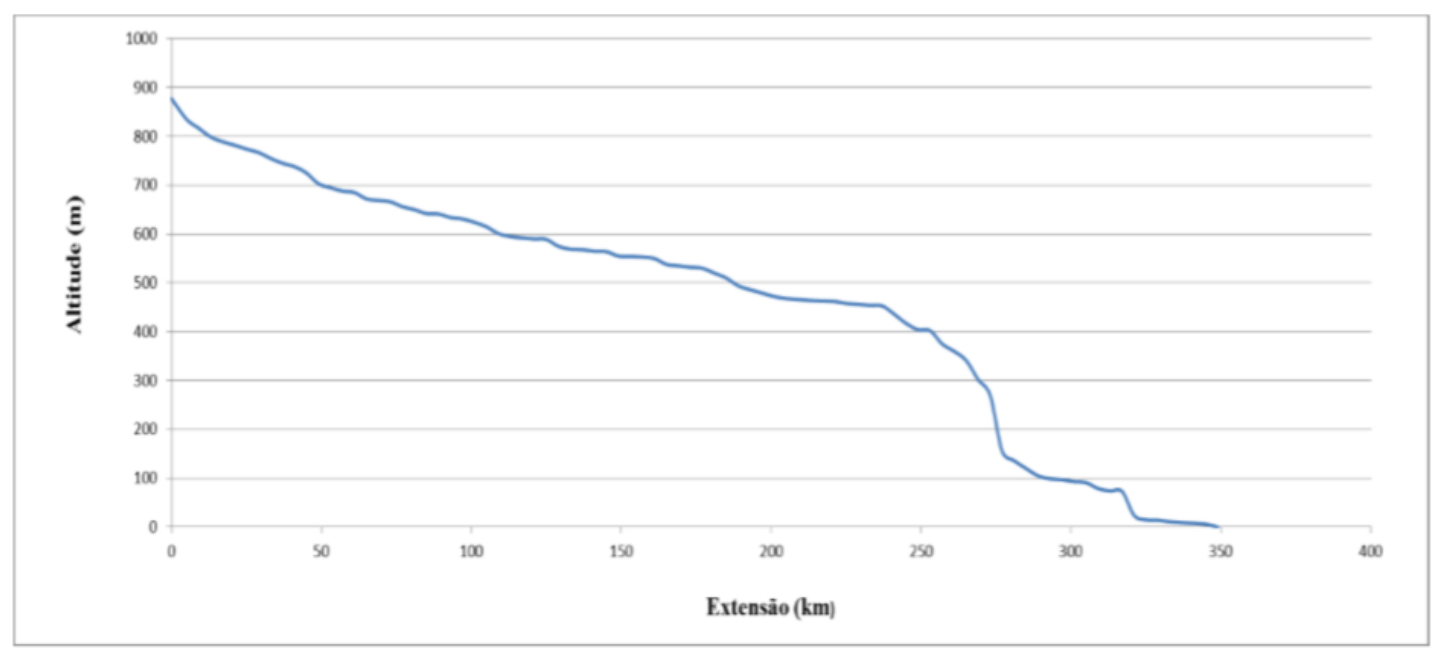

Figura 4 - Perfil Longitudinal do Rio Ipojuca. Fonte: Silva et al (2014)

\section{CONSIDERAÇÕES FINAIS}

Os resultados obtidos com a pesquisa caracterizam um começo de análise morfométrica e servem de aporte para considerações futuras, onde a partir desse ponto é necessário buscar os padrões da densidade de drenagem da bacia para assim se obter uma análise morfométrica mais completa e que contribua de forma significativa para o arcabouço teórico da ciência atual sobre o objeto de estudo.

O trabalho não buscou se aprofundar no quesito densidade de drenagem e opta por trabalhar de forma mais incisiva nas características morfológicas da bacia, dando ênfase ao fator forma e descrevendo atributos físicos-estruturais do objeto de estudo, desde sua área total, passando pelo perímetro, comprimento do canal principal, comprimento total dos canais, perfil longitudinal e aprofundando mais ainda nos padrões de declividade, mostrando a realidade da bacia onde predomina um relevo plano com baixa declividade média, e utilizando como base uma hierarquia fluvial para extração desses dados.

Todos os dados trabalhados oferecem base para compreensão da bacia como um todo, e atuam como contribuições iniciais para pesquisas morfológicas na bacia hidrográfica do rio Ipojuca. Os mesmos oferecem compreensão das características físico-naturais e geomorfológicas da bacia, além de servir como banco de dados para o laboratório de Geoprocessamento e Modelagem Ambiental da Universidade de Pernambuco.

\section{REFERENCIAS}

CASTRO, S. S. ; CARVALHO, T. M. Análise Morfométrica e geomorfologia da bacia hidrográfica do rio Turvo - GO, através de técnicas de sensoriamento remoto e geoprocessamento. In: SCIENTIA PLENA, Vol. 5, Num. 2, 025401, 2009. 
NASCIMENTO, F, I, C; SANTOS, W, L; LIRA, E, M; ARCOS, F, O. Caracterização Morfométrica como Base para o Manejo da Bacia Hidrográfica do Rio São Francisco - Acre. Revista Brasileira de Geografia Física, Recife, V.06, N.02 (2013) 170-183, 2013.

GOMES, D. D. M.; DUARTE, C. R.; VERÍSSIMO, C. U. V.; LIMA, D. R. M. Análise e Compartimentação Morfométrica da Bacia Hidrográfica do Rio Mundaú - Pernambuco/Alagoas. Revista de Geologia, Fortaleza, Vol. 27, n 2, 167 - 182, 2014.

GOMES, D. D. M. Geoprocessamento aplicado à análise e zoneamento dos sistemas ambientais da bacia hidrográfica do Rio Mundaú - PE/AL. Tese de Doutorado apresentado ao Programa de Pós-Graduação em Geologia da Universidade Federal do Ceará, Fortaleza, 2015. 240 p.

LIMA, A. G. A bacia Hidrográfica como Recorte de Estudos em Geografia Humana. GEOGRAFIA, v. 14, n. 2, jul./dez. 2005 - Universidade Estadual de Londrina, Departamento de Geociências.

SILVA, R. N.; GOMES, D. D. M.; GOLDFARB, M. C. Determinação e Análise do Perfil Longitudinal do Rio Ipojuca (PE). In: XXVI Congresso Brasileiro de Cartografia, At Gramado / RS, Volume: 1 - 2014.

Bacia Hidrográfica do Rio Ipojuca: Series de bacias hidrográficas de Pernambuco, $\mathrm{n}^{\circ}$ 1. I Wellington Eliazar da Silva (Coordenação). Agência Condepe/Fidem. Rio Ipojuca. Recife: 2005. 64p. (Série Bacias Hidrográficas de Pernambuco). http://www.condepefidem.pe.gov.br/c/document_library/get_file?p_1_id=78673\&folderId=141869 \&name=DLFE-12005.pdf. Acesso realizado em: 15/09/2016.

HORTON, Roberte., Erosional development of streams and their drainage basins: hydrophysical approach to quantitative morphology", Geol. Soc. America Buelletin (1945), 56 (3), pp. 275-370.

STRAHLER, Arthur N., "Hypsometric (area-altitude) analysis of erosional topography. Geol. Soc. America Bulletin (1952), 63, pp. 1117-1142.

STRAHLER, Arthur N., "Quanttative analysis of watershed Geomorphology", Amer. Geoph. Union Trans. (1957), 38, pp. 923-920.

STRAHLER, Arthur N., "Dimensional analysis applied to fluvial eroded landforms", Geol. Soc. American Bulletin (1958), 69, pp. 279-300.

Cenas SRTM, Disponível em: <http://www.relevobr.cnpm.embrapa.br/download/>. Acesso em 12 de setembro de 2015. 


\section{AGRADECIMENTOS}

Os autores agradecem a Universidade de Pernambuco (UPE) pelo financiamento dos recursos do projetos de pesquisa "Diagnóstico geoambiental das bacias hidrográficas do Estado de Pernambuco: geoprocessamento aplicado ao manejo e conservação dos recursos naturais", junto ao Programa de Fortalecimento Acadêmico (PFA/IC), e ao Laboratório de Geoprocessamento e Modelagem Ambiental pela cessão dos dados cartográficos vetorizados e imagens de satélites.

Recebido em: 14/08/2016

Aceito para publicação em: 01/10/2016 